\title{
Under Surveillance? The Impact of \#MeToo on Sexual Correctness and Men at Work
}

\author{
Nicole Graham, James Bowness
}

\begin{abstract}
In challenging everyday sexism, the \#MeToo movement calls for a recalibration of sexual correctness which impacts not only the private sphere, but even more so the public spaces of social life such as the workplace. This article examines men's experiences of the \#MeToo movement, aiming to explore what impact the phenomenon has had on workplace gender relations. Our study adopts a qualitative research design to capture the experiences of ten men across a mix of gendered workplaces in Scotland. Drawing upon a Foucauldian feminist framework, we argue that the \#MeToo movement calls for new forms of (self) governmentality within men. Our data suggest that men not only police each other in the workplace but have drawn upon technologies of self to carve out workplace spaces where they can continue questionable behaviours. These technologies relate to the management of language and the vetting of colleagues. We also detail how men hold contradictory opinions of the \#MeToo movement with many showing solidarity with its aims. As such, the men were divided by their willingness to adhere to new workplace politics. We conclude by commenting on the impact of this media-driven movement that aims to challenge problematic masculinities.
\end{abstract}

KEYWORDS \#MeToo, masculinities, workplace masculinity, Foucault, crisis of masculinity

\section{Introduction}

In 2017, the "\#MeToo" movement became a shockwave social media crusade, supporting the exposure of those who allegedly violate the social value of sexual consent while highlighting the scale of sexual harassment, assault, and rape in Western societies (Civitello 2017). Founded by grassroots activist Tarana Burke, the movement existed for more than a decade prior to becoming a global phenomenon, aiming to empower survivors of sexual victimisation (particularly young black women) by collectively revealing the intersubjective experience of sexual violation (Civitello 2017). The movement became a global phenomenon following actress Alyssa Milano's tweet in 2017, which invited survivors of sexual violation to join her in stating "\#MeToo" on social media platforms (Parker 2017). More than 40,000 people responded directly to Milano's tweet, and by late 2017, \#MeToo had been retweeted 23 million times in 85 countries (Collins 2020).

In an act of transnational solidarity, the hashtags "\#YoTambien" and "\#quellavotache" emerged in Spain and Italy, while twelve million adopted the Francophone hashtag,

Sociálnístudia / Social Studies 2/2021. S. 11-29. ISSN 1214-813X. https://doi.org/10.5817/SOC2021-2-11 
"\#BalanceTonPorc", translating to "expose your pig" (Burke 2018). Indeed, Zacchia, Corsi and Botti (2020) note that the glocalised versions of the \#MeToo hashtag gained more traction than the global \#MeToo within several European nations (their work explores localised versions of the movement in France, Germany, Italy, Spain, and Sweden). Much like their Western counterparts, the impact of \#MeToo reached Mexico, India, Pakistan, and Egypt, placing gender and power relations on the public agenda (Collins 2020), and women from varied backgrounds shared their experiences (Thissen 2019). Consequently, the European Ombudsman proposed a list of best conduct practices based on a review of the anti-harassment policies in $26 \mathrm{EU}$ institutions, ranging from awareness raising to swift procedures and rehabilitation measures to combat gender-based harassment and violence within workplaces (Thissen 2019).

The proliferation of the "\#MeToo" movement was the backdrop for a series of public allegations of sexual misconduct made against powerful individuals in Western society. The Weinstein scandal was the catalyst; exposing the power relations involved as those in elite positions sexually exploited their victims by promising career prospects in return for sexual activities, which was not limited to heterosexual encounters (Burke 2018). In the wake of \#MeToo, Boyle (2019) argues that the outward social media discussion of sexual harassment, rape and assault aligns with second-wave Feminist consciousness-raising practices. Elsewhere, Loney-Howes (2019) charted the evolution of the \#MeToo movement and its journey through previous forms of anti-rape activism that followed the second wave of Feminism. Others have addressed the backlash against the \#MeToo movement, including the reactionary male-orientated \#HimToo movement (Boyle and Rathnayake 2019) and terms such as "sexual correctness" have multiplied as an argument against \#MeToo (Williams 2017). The term "sexual correctness" is not new and captures normative values relating to "correct" sexual conduct. This includes how individuals treat each other within marriage, what comments strangers make to each other on the street, and what subjects are acceptable to discuss in the workplace (McElroy 1996). As such, "\#MeToo" not only encouraged sexual harassment survivors to share their experiences but also called for a recalibration of sexual conduct in public and private spaces.

In challenging existing gender relations, the \#MeToo movement has also shattered he "culture of silence" surrounding sexual victimisation (MacMillan 2013). The workplace is one social space that suffers from "everyday occurrences" of sexual harassment (House of Commons 2018). At the heart of it, the \#MeToo movement challenges a form of masculinity that perpetuates the everyday occurrence of sexual harassment. Critics of the movement argue that it shifts focus from more serious forms of victimisation by blurring the lines of sexual conduct while also reproducing the "women-as-victim" narrative (Williams 2017). Others have suggested that the \#MeToo movement has weaponised women, creating a hostile working environment for men (Burnett 2018). These accounts often reproduce notions of a "culture of fear" (Furedi 1997), which overstates the male threat and overestimates the dangers women face. Much of this language adjoins an existing narrative that situates men at the centre of a "crisis of masculinity" (Griffin 2000; Singleton 2008).

This paper explores the impact of the \#MeToo movement on the lived experiences of men in workplaces in Glasgow, Scotland. We first frame our conception of masculinity 
through the work of Robert W. Connell, before examining the ways in which shifting labour relations have contributed to a perceived crisis of masculinity. We then detail our theoretical framework and methodological approach. Later we explore what men know of the \#MeToo movement and how they perceive it to impact their workplaces. We conclude by using Foucauldian theory to make sense of the experiences and perceptions of our participants. We argue that the \#MeToo movement has led to a new productive form of surveillance that operates within and among men in the workplace.

\section{Masculinity and Crisis}

The study of men and masculinities is dominated by the work of Connell (1992, 2005; Connell and Messerschmidt 2005). Connell (2005) presents a pluralistic conception of gender, situating masculinity within a hierarchal structure. Borrowing from Gramsci (1971), Connell (2005) uses the concept of "hegemony" to explain how one form of masculinity "claims and sustains a leading position in social life" (p. 77). The dominance of a form of masculinity is upheld through social interactions and, for Connell (2005), is perpetuated via power, production, and cathexis relations. Power relations, with which Connell (2005: 74) associates the "patriarchy", ensure the dominance of men and subjugation of women. Production relations relate to the gendered division of labour, which associates men with economic expertise and the reproduction of a capitalist system that produces rewards unequally along gendered lines. Cathexis relations refers to directed sexual desire which maps onto an existing gender order to reproduce desired bodies (Connell 2005).

In Western society, hegemonic masculinity is characterised by whiteness, mandatory heterosexuality and economic success (Roberts 2012), whilst aggression, dominance, heterosexual prowess and emotional restraint are also associated with hegemonic forms of masculinity (Connell and Messerschmidt 2005). Men who do not conform to these behaviours are penalised with a marginalised masculinity status associated with behaviours rendered as "feminine", and therefore subordinate (Connell 1992, 2005). Furthermore, few men meet the ideals of hegemonic masculinity, yet receive patriarchal benefits through the presentation of a complicit masculinity that tolerates hegemonic ideals. Connell (2005) argues that these men benefit from a "patriarchal dividend" which provides an advantage to all men over women by being complicit in the continuation of the existing gender order. Connell's (2005) gender order is inherently fluid, with the characteristics of hegemonic, marginalised, and subordinate masculinities changing over time.

The workplace, with its changing dynamics, is one sphere of social life that has seen a recalibration of the gender order (Walby 2003). Processes of deindustrialisation have led many to argue that labour has undergone processes of feminisation (Standing 1999; Morini 2007). In relation to deindustrialisation in the UK, Winlow (2001) suggests that men have been forced to find employment in service sector roles that are often associated with traditional notions of femininity. Others argue that the impact of this change is exaggerated, with McDowell (2000) arguing that many of these men continued to fulfil familial obligations. Evidence suggests that men in female concentrated roles develop an expression of masculinity that allows them to function cooperatively in the female domain (Cross and Bagilhole 2002; 
Bagilhole and Cross 2006; Lupton 2000; McDowell 2000). Accordingly, men perform "female" roles without losing a sense of "manliness" (Lupton 2000). For example, research on men in the nursing profession suggests that men discard hegemonic models of masculinity (McDowell 2015). Although these accounts undermine a conceptualisation of these changes as a negative situation for men, a discourse of masculinity in crisis continues to fester (Jordan and Chandler 2018).

The "crisis of masculinity" discourse has been longstanding within popular culture, media, and politics (Jordan and Chandler 2018). Various issues have been constructed as symptomatic of the "crisis of masculinity" such as academic underachievement by boys (Griffin 2000; Singleton 2008), men's unemployment (McDowell 2000; Hopkins 2009), the breakdown of the nuclear family structure (Singleton 2008), fatherhood issues (Jordan 2014), men's mental health issues (Loughran 2013), and most recently, the surge of male suicide (Jordan and Chandler 2018). Some have argued that crisis narratives have been deployed to serve particular ideological perspectives (Singleton 2008), as a pushback against challenges to hegemonic notions of masculinity (McDowell 2000). Many scholars have attributed the surge of "crisis" rhetoric to a backlash against "girl power" (Singleton 2008), which carries significant connotations of "unfair privilege" awarded to girls (Griffin 2000). As Jordan and Chandler (2018) highlight, such narratives can be divided into conservative and progressive accounts. Conservative narratives position the crisis of masculinity as a consequence of "threats" to the traditional gender roles, whereas progressive accounts use the "symptoms" of the "crisis of masculinity" as evidence that existing gender roles are harmful and thus should be altered (Jordan and Chandler 2018). Conservative narratives of the "crisis of masculinity" are positioned as anti-feminist, while progressive accounts believe that a re-balancing of gender relations is desirable.

The \#MeToo movement aims to problematise certain forms of masculinity, situating the crisis along the lines of Jordan and Chandler's (2018) progressive account. To do so, the movement relies upon engagement with contemporary media to challenge the hegemonic masculinity which is consistently depicted in the media (Evans and Davies 2000), with male characters often showing aggression (Giaccardi et al. 2016). In relation to sexuality, research suggests that in the media men are often presented as having uncontrollable sexual urges (Ward 1995), holding homophobic views, and challenging the masculinities of other male characters (Kim et al. 2007). While media portrayals often fit neatly within the parameters of Connell's (2005) hegemonic masculinity, the \#MeToo movement has provided a mediatised environment that challenges various tenants of this dominant form of masculinity. We argue that the emergent \#MeToo movement challenges the existing gender order and calls for the creation of a more progressive masculinity. Aside from challenging dominant discourses of masculinity, some have insisted that the \#MeToo movement can and should have an impact on the division of labour in media - that is, who gets to star in contemporary media and who gets to direct and produce such outputs (Verhoeven, Coate and Zemaityte 2019).

As a relatively new phenomenon, limited research has explored the \#MeToo movement. Due to the changes in labour markets described above, we argue that exploring the impact of the \#MeToo movement on contemporary workplaces is timely. With gender relations in flux, it is fitting to ask the following research question: 
In the wake of the \#MeToo movement, what impact has the sexual surveillance of men had on the performance of masculinities within the workplace?

To answer this question, we draw upon a case study of various workplaces in Scotland's largest city, Glasgow. This location was primarily chosen out of convenience for both researchers, but also took place against the backdrop of the high-profile criminal case involving former Scottish First Minister, Alex Salmond. Salmond had been the First Minister of Scotland between 2007 and 2014, stepping down shortly after failing to win Scotland's independence referendum in September 2014. Allegations against Salmond were made in August 2018, and he was arrested with 14 charges in early 2019. In 2020, Salmond was found not guilty of 12 charges, not proven on one charge, and the last was dropped by the prosecution. The case chimed with many tenets of the \#MeToo movement, that is, a powerful privileged male was accused of improper sexual conduct. Glasgow was one of only four political constituencies that had backed Salmond's independence movement in 2014. As such, Scotland's biggest city had collectively backed a high-profile politician's movement three years prior to the global \#MeToo moment and only four years prior to the allegations made against Salmond. For this reason, we believe that Glasgow provides a case study location with clear links to the subject matter around \#MeToo.

To understand the experiences of men working in Glasgow, we utilise a Foucauldian feminist framework to make sense of how the \#MeToo movement has impacted men within the workplace, a framework we will now detail.

\section{Foucault, Gender and Surveillance}

Various feminist authors have drawn upon Foucault's ideas on power and governmentality in their analysis of women in society (McNay 1992; Bartky 1998; Tretheway 1999; Hess et al. 2015; Fernandez-Morales and Menendez-Menendez 2016; McCarthy 2017). Foucault's (1980) thesis is that power is no longer primarily exercised explicitly and is instead more implicit within social systems. Traditional forms of sovereign power used brute force, while modern forms of power use discipline to coerce populations (Foucault 1980). For Foucault, the economic transformation of the eighteenth century led to the disciplining and organising of time, space, bodies, and populations. In the move to biopolitics, disciplinary action is enacted implicitly by citizens, concealing sources of power from above. Foucault traces such ideas back to the Panopticon prison design of Jeremy Bentham, a model which captures the essence of the disciplinary society (Bartky 1998). The Panopticon is a circular building with a tower in the centre and windows that open into the inner side of the ring. The design prevents prisoners from knowing if they are being watched, as the prison guard is hidden. The obscured nature of power produces a disciplinary "gaze" that forces individuals to discipline themselves (Foucault 1980). The ever-present nature of the gaze renders the body "docile"; a malleable object managed by power structures that have become increasingly hidden (Foucault 1975).

This conception of power has been applied within Foucauldian feminist thought to conceptualise the gaze as patriarchal. The gaze is understood as a form of male power which forces women to perform accepted modes of femininity (Bartky 1998). Bartky (1988) argues 
that modern dietary regimes that curate the female body and cosmetics that style the female body's looks are both processes of a gaze which is gendered. Furthermore, like Bartky (1988), Young (1980) argues that the patriarchal gaze impacts upon bodily comportment, changing how the female body operates in space. This form of feminine discipline is most visible in a woman's typical posture; legs are crossed or touching while arms are close or across the body (Tretheway 1999). Therefore, a woman's restrained posture is the physical expression of her subjugated position which is unconsciously performed and encouraged by the "male gaze". Bordo (1989) also uses a Foucauldian perspective on power to argue that the social construction of the female body is a result of gendered power and surveillance. Therefore, feminist uses of Foucault's ideas on power, discipline and surveillance conceive of the female body as controlled, marginalised, and subordinate.

Men are also impacted by the "male gaze". The hegemonic construction of masculinity requires men to perform masculinity, with non-conformity resulting in a marginalised masculinity status (Connell 2005). Boys use "punking" and a "fag" discourse to heighten their own individual masculinity status (Pascoe 2007; Philips 2007). "Girl watching" in the workplace occurs in the presence of a male audience to affirm one's masculine status (Quinn 2002), and "girl hunting" is a collective performance by men which is used to gain approval from peers (Grazian 2007). Thus, the sexual objectification of females is a form of impression management, used to perform heterosexuality and thus masculinity to other men (Grazian 2007). These behaviours are often the result of homosocial environments in which the hegemonic values of masculinity are reproduced (Flood 2008).

Critiques levelled at Foucault's early work of discipline argue that it fails to offer a gendered account of how docile bodies are experienced (Bartky 1988) and how gendered resistance is produced (Deveaux 1994). Fox (1998) argues that the top-down conception of power, albeit implicit, is deterministic. Indeed, Deveaux (1994) argues that those who have used Foucault's early writings on power seem to reproduce a universal conception of the female body as entirely passive, controlled, and managed. What is missing from such accounts is those emergent femininities, perhaps still in the minority, which challenge such understandings. Women now develop muscular bodies (Bunsell 2013), lesbian communities are rejecting heterosexuality (Bartky 1998), high-profile women are disregarding cosmetic application (Blair 2017), and most significantly, women are publicly objecting to sexual victimisation - as evidenced in the "\#MeToo" movement. Such movements symbolise acts of resistance to the very forces of surveillance detailed above.

To understand these acts of resistance, Foucault's revised work on power and discipline (1988) and the concept of technologies of self are of particular use. Technologies of self relate to the ways in which individuals self-regulate in order to create "a certain state of happiness, purity, wisdom, perfection of immortality" (Foucault 1988: 16). Whereas the above conceptions of self-discipline conceive of the body as passive, technologies of self act upon the individual to create new productive realities. As such, empowerment often requires technologies of self to overcome existing social barriers.

Foucault's writings on discipline are useful to our project in two ways. Firstly, we contend that the \#MeToo movement acts as a form of discipline that uniquely situates men within a female gaze. As such, Foucault's earlier conceptions of power can be used 
to understand how, if at all, masculinities are disciplined within the workplace. Secondly, Foucault's later conceptualisations of power can be used to frame the ways in which men manage these new forms of surveillance through self-regulation. We argue that men now find themselves at the intersection of two contradictory gazes, one of which aims to reproduce hegemonic forms of masculinity and another which aims to challenge such normative ideas of what men should be. The ideas of "technologies of self" allow us to comprehend how men react, positively and negatively, to a location where these disciplinary forces operate: the workplace.

\section{Methodology}

We utilised a qualitative approach involving interviews with men across a variety of workplaces. Data collection took place in early 2019 and was completed by the first author. The second author advised throughout the research process and aided in data analysis and write up. As both researchers live and work in Glasgow, the city was a convenient place to complete workplace-based research.

\section{Participants}

We used generic purposive sampling (Allan and Eatough 2016) to produce a small case study to explore the experiences of men in the workplace. Our sample consisted of participants identifying exclusively as male and employed full time within the city of Glasgow. Consistent with the idiographic character of IPA and qualitative research, small sample sizes were adopted (Allan and Eatough 2016). In total there were ten participants: four employed within male dominated workplaces (construction and engineering) and six employed within mixed-sex workplaces (public sector office environments). Those employed within the mixed-sex workplaces interacted with female colleagues more often than those in male-dominated workplaces, although both groups interacted with the public. In mixedsex workplaces, professional relationships varied between participants and female staff; some were colleagues, superiors and subordinates to the participants. In contrast, female staff in the male-dominated workplaces did not work alongside the participants who worked off-site; the female staff was typically based in the office. Our participants were aged from twenty-four to sixty years old, with an average age of 41.5 years $( \pm 15.6)$. Eight participants were white British with two identifying as white British/Italian.

\section{Procedure}

Semi-structured interviews lasting from forty to sixty minutes were used to explore what participants knew of \#MeToo and their perceptions of how it had impacted upon their workplaces. Interviews were recorded and transcribed verbatim. For participants employed within mixed-sex workplaces, the interviews were conducted in a private office at the workplace. However, access to the male-dominated workplaces was not available and thus interviews were conducted on the first author's university campus. Participants 
were asked a series of twenty open-ended questions on the participant's understandings of sexual correctness in the workplace. Additional probing questions were used throughout to ascertain the subjective experiences and perceptions of each participant.

\section{Data Analysis}

An interpretative phenomenological analysis (IPA) was used to identify, analyse and report patterns in the data. IPA has previously been used for analysis on sensitive topics (Allan and Eatough 2016; Back et al. 2011; Knight et al. 2003). The first author transcribed the interviews verbatim and read the transcripts several times for familiarisation. As Johnston and Morrison (2007) stipulate, the transcripts were read thoroughly until the researchers identified developing themes which were the result of coding that was written in the margins. The elicited themes were recorded in a different file and examined for convergences and divergences (Johnston and Morrison 2007). Comparisons were made between the participants employed at male-dominated and mixed-sex workplaces for areas of similarity and difference, and examples of the themes from the participant's accounts were then documented alongside their relevant themes (Johnston and Morrison 2007). This resulted in a document showing developing themes with excerpts from the accounts of the interviewees, which ensured that the thematic interpretations correctly mirrored the interviewees' individual accounts (Johnston and Morrison 2007). For the purpose of ensuring rigour, the second author provided a constructive critique of the first author's analysis. We conceive this as an example of researcher triangulation that aids the credibility of qualitative data analysis (Lincoln and Guba 1985).

\section{Positionality and Reflexivity}

Following the principles of feminist and phenomenological research, the investigation sought to ensure that an egalitarian relationship between the researchers and the researched was established (Grbich 2013). As author one is female and was interviewing males on sensitive topics, this posed significant challenges. There are various studies which claim that when women interview men, the interview becomes burdened with gendered performances and power struggles (Campbell 2003; Pini 2005; Gailey and Prohaska 2011). To overcome this, a reflexive position was adopted. England (1994) states that reflexivity is a self-critical introspection by the researcher involving scrutiny of the self. Thus, in this project, author one was aware of her historical, cultural, and political position of being female and the power dynamic of interviewing males. Throughout interviewing, author one presented an impartial stance and at no point suggested particular male behaviours were inappropriate or deviant.

The analysis produced two key themes detailed below. These themes describe the ways in which participants understood the \#MeToo movement as a form of feminist discourse and the ways in which such ideas permeated workplaces and altered at-work behaviour. 


\section{Feminist Discourse as a Threat}

Our first theme explores perceptions participants had of feminist discourses associated with \#MeToo. Positive and negative accounts of feminism as a threat to men and masculinity were present in the participants' accounts. Various participants disclosed their fear of entrapment, while also suggesting this was a plausible risk. They also discussed the consequences of such entrapment. An example comes from Alex (60, MSW):

I like a lot of banter - it gets your working day by, but it makes you much more ... cautious on what I say and who I say it to, and it's got to be at the right time, right place, and right environment, so it's not misconstrued.

I've had to be cautious and more careful because I don't want to leave myself open to accusations of, you know, "he was sexually harassing me", so I'm very much cautious in that line because of the amount of allegations that are happening.

The fear and risk of entrapment and sanction was echoed in the words of Todd (48, MSW), who believed that not all cases of sexual misconduct are true, a reproduction of a popular rape myth (Suarez and Gadalla 2010). Furthermore, Todd situated these ideas within seemingly innocent situations such as the sharing of office space:

You don't want to get yourself in a situation that could be misconstrued ... you know that kind of thing, in the stationery cupboard [laugh].

... I'm going to say Cliff Richard for example, his were completely false allegations so not every allegation is true ... but every male is seen that way.

Participants who believed feminism was a negative threat to men detailed a sharp awareness of sexual misconduct cases in the media, a fear of their own behaviours being misconstrued, and a risk of being sanctioned through false accusations of sexual misconduct in the workplace. Various participants also expressed a fear of being disciplined or losing their jobs through false allegations, as demonstrated below:

I've heard stories of how one inappropriate touch on the shoulder can lead to a female going to the manager and I just feel as if that's taking it a step too far. (Robert, 25, MSW)

I'm lucky that I get away with it,' but I know in the back of my head, it only takes one person to complain and that could be me losing my job. (Paul, 55, MSW)

One consequence of fear and risk awareness was that many of the participants believed themselves to be part of a group demonised by society, a phenomenon known as the "demonization of men" (Hooks 2000). Participants exhibited a sophisticated understanding of feminist thought, which protects the basic principle of gender equality, whilst attacking

Paul uses the term "get away with it" referring to the acceptance of his form of banter which he recognised would be, in other spaces, somewhat controversial. 
the radical strand of feminism - believing that radical feminism pressurises men and creates a subsequent "crisis" effect on masculinity, as detailed in the words of Johnathon (24, MDW):

You could look at it as a sort of demonization of men which is one way that it has been ran from. Eh, but I think that only sort of applies to sort of far-leftish ideologies.

... But then you have this wee minority of feminists, and I say that pretty loosely because they're not feminists, they're demonizing men and saying that all men are the problems of this and that.

Johnathon demonstrates a nuanced understanding of narratives that surround the "crisis of masculinity". He draws upon what Jordan and Chandler (2018) highlight as a conservative narrative of the "crisis of masculinity", that is that men are unfairly challenged by feminism, but he suggests that this is a minority position within the feminist perspective. A similar position is taken by Thomas (48, MSW), who first comments on the overly aggressive response of men to feminism before discussing the benefits of contemporary feminism:

... you know terms like "Feminazi", which I just think is incredible! And that's just something that's came out recently that's not something that's going right back to when there was a kind of rejection of the women's movement ... The impact it has had I suppose is the surprise of the reaction of people who are ultimately trying to reject it.

I think the impact that it has on me is that people are actually paying attention to it now. I think that's a good thing, I think it was dismissed, it still is currently dismissed in a lot of circles.

Previous literature has identified that progressive accounts of the "crisis of masculinity" rhetoric reflect elements of feminism, and thus aim to dismantle gender roles to produce equality in society (Jordan and Chandler 2018). Thus, some men expressed that sexual correctness was a positive outcome for men by producing progress in society for men and women alike. As such, we identified a mixed response in how our participants understood the outcomes of "feminism". Generally, we noticed that participants tend to split in the way that Jordan and Chandler (2018) conceive the crisis of masculinity. On the one hand, some participants see men under threat from feminist ideas whilst others think that the time is right for a change in what it means to be a man. How these ideas extend from belief into behaviour within the workplace is where we now turn.

\section{Workplace Surveillance and Behaviour Change}

Our second theme demonstrates the ways in which men believe their workplace behaviours changed in response to \#MeToo. One of the main sub-themes we elicited was the implicit belief that workplaces are spaces of surveillance that force men to consider their workplace behaviour. Various participants believe that workplaces are now dominated by forms of surveillance that were hitherto absent. Whereas in the past surveillance may have come from specific actor such as a manager, a more general form of discipline is voiced by our participants. An example comes from Alex (60, MSW): 
Scrutinised, not so much from your line management - there's no difference in attitude there... but they are getting scrutinised in general in what they say, how they act and what their attitudes are towards the female sex.

As such, many are unable to pinpoint where such disciplinary power comes from. Power is conceptualised as hidden yet productive. One way in which this hidden power operates is via language. That is, participants discuss how interpersonal communication is an area that requires consideration. As such, the control of language is a key element in self-policing behaviour:

I work in an organisation that is about $80 \%$ female, so you've got to watch your language, you've got to watch what you do, your actions and stuff like that and make sure it's appropriate. (Todd, 58, MSW)

If my apprentice did something wrong then I might call him a fucking idiot or something like that, know what I mean? But I wouldn't go and say that to a woman because ... you just don't do that. (Marcus, 24, MDW)

For new people that come in, I watch what I say to them ... I am wary of new people that are in the office. (Paul, 55, MSW)

The quotes above detail a variety of situations in which the control of language is required. Marcus demonstrates restraint in how he might reprimand a colleague, whilst Paul notes a wariness in engaging with new people. Another element of self-policing behaviour is having "fun". Some participants say they negotiate internally which colleagues are suitable to have "fun" with, and therefore judge when the "gaze" is upon them. This often means that homosocial environments are safe spaces to have "fun":

Aye so like if you're just having a bit of fun with your pals, you're not really going to share that with females. (Michael, 24, MDW)

Michael's comment demonstrates how implicit his homosocial network is; females and pals are presented in contrast rather than as overlapping categories. On the other hand, various participants note how strong relationships between co-workers sometimes break down gendered barriers in the workplace:

No, I take them as if they are men [laugh] ... Just the way we talk, nope, I wouldn't treat them any different at all. (Paul, 55, MSW)

Indeed, Paul's comment suggests that although he may be careful with his language in relation to outsiders, those within his close circle are treated equally irrespective of gender. These ideas demonstrate the ways in which men regulate their behaviour in order to conceal a particular form of masculinity that they understand to be controversial for some individuals. On the other hand, participants also note how they police others' behaviour, not to reproduce hegemonic masculinity norms but to challenge these behaviours, as voiced by Cameron (44, MSW):

It's just made me a bit more aware of the behaviours of other people ... But, yeah, it does definitely heighten your awareness that these things have gone on in the past. 
Such awareness may lead to internal self-disciplining. For example, at times the men were "tipped off" about a male colleague and encouraged to intervene to challenge negative behaviour. An example comes from Peter (54, MDW):

To be honest with you, we had a wee situation where one of the guys that was with us, he was a bit of a "jack the lad", and there was a young girl that worked with us at the time and the manageress said to me "can you keep a wee eye on him".

Other men discuss behaviours that at face value appear deviant, yet have their own individual meaning. Thomas expresses such a nuanced position (48, MSW):

I've seen, or overheard other members of staff speaking to females, for example the two individuals that I'm thinking of have known each other a long time and so the way they express themselves ... if a stranger walked past and overheard what they were talking about they might just think "what the hell is going on". (Thomas, 48, MSW)

Others also identify particular types of women with whom they do not need to manage their behaviour. These ideas cluster around individuals who perform more masculine femininities, whether through language, dress, or sexuality. In such cases the men do not feel the need to self-manage their workplace behaviour:

It's different if the girl is a lesbian or bisexual or something and had a bit of a boyish way about her. [hesitation] I mean it's a girl that cuts my hair, and she is a lesbian. We have bit of banter and chat and stuff because it's the same kind of chat I'd have with my pals. (Michael, 25, MDW)

Michael's comment aligns with previous literature that notes how institutionalised heterosexuality assumes that all women must present themselves as objects of the male "gaze" (Bartky 1998). However, women who do not conform to normative notions of femininity and do not perform female masculinity present an alternative manifestation of masculinity (Nguyen 2008). Hence, female masculinity transgresses normative femininity and in Michael's case presents itself as a symbol of safety.

It was clear to us that the men understand the \#MeToo movement as symbolic of feminist discourse more generally. This stimulated a change in the interpersonal relationships in the workplace. We now discuss the implications and consequences of these findings using a Foucauldian lens.

\section{Discussion}

The data above demonstrate that in the current cultural climate of increased scrutiny of gender and power relations, men in both mixed-sex and male-dominated occupations feel, or are aware of being under, "sexual surveillance". The findings gathered from both the mixed-sex and male-dominated workplaces were not significantly different. Minor differences were that those employed within the mixed-sex environment demonstrated, to a greater extent than those in male-dominated occupations, self-policing behaviour. This is perhaps due to such men encountering female colleagues more often than those in male-dominated occupations. However, both groups demonstrated that there is widespread belief that significant changes 
in gender relations and gender performativity are ongoing in contemporary society and overt expressions of heterosexual prowess are being challenged by men and women. However, there are differing views whether the sexual correctness phenomenon confines men within, or liberates them from, the hegemonic construction of masculinity. This finding resonates with previous literature exploring the changing nature of contemporary masculinities.

\section{Masculinity in Flux}

The belief that the display of heterosexual prowess is predominately performed by older generational colleagues resonates with previous literature identifying how traditional masculinity has transformed due to economic, political, and social changes (Snikter et al. 2018; Winlow 2001; McDowell 2000). Some of the younger participants voice more progressive accounts of masculinity that situate the \#MeToo movement as an awareness raising movement. These participants do not perceive heterosexual prowess as "manly" but more as "predatory", and hence some of the men themselves problematise such behaviour. Due to this change, there is a collective awareness that masculinity is in flux, undergoing significant changes that men are aware of and trying to adapt to. Thus, those who perform behaviours such as heterosexual prowess are being policed by others (potentially male and female). Therefore, the new wave of feminism is encouraging some younger men to support the threat of feminism to the hegemonic construction of masculinity, while challenging older generational colleagues to conform to the behaviour of the contemporary generation.

These changes situate sexual correctness as both a confiner and liberator of men. Both approaches situate hegemonic masculinity as fluid, prone to change, and contested (Connell 2005). We therefore argue that the mediatised approach of movements such as \#MeToo act as a stimulus in the remaking of hegemonic masculinities. In an emancipatory sense, one line of thought is that sexual correctness liberates men from conforming to the hegemonic construction of masculinity, as men are no longer be required to conform to traditionally "masculine" behaviours, which provides freedom to the individual. On the other hand, others present the contemporary landscape as one of confinement, driving men to selfdisciplinary action. It is to this narrative that we believe the work of Foucault provides much explanatory value.

\section{The Confinement of Men?}

The self-policing behaviours detailed here reflect Foucault's (1980) conception of modern forms of power. That is, power that is exercised through surveillance which scrutinises individual's bodies, actions, and gestures; essentially creating implicit social control as individuals internalise the gaze, thus leading to conformity even if the gaze is not upon them (Foucault 1980). Hence, it could be argued that a feminist "gaze" has emerged in the form of the sexual surveillance of men, which operates within workplace social interactions. Thus, there is not an explicit actor that can be identified as the power holder, since power is dispersed across society. In the sense of the \#MeToo movement, we argue that its power lies 
in its ability to operate at a discursive level. Although high profile individuals such as Harvey Weinstein have been brought to trial and prosecuted, the impact of the \#MeToo movement is not reliant upon an individual power broker. Instead, the scrutiny present within such a discourse has led some men to internalise the "gaze" in order to prevent any transgressions. The "gaze" scrutinises male behaviour, action, and attitudes towards women, creating selfpolicing behaviours among men due to either their agreement with sexual correctness, or fear of accusation, a by-product of the sexual correctness phenomena.

The policing of other's behaviour aligns to the previous literature which illustrated that men often exercise gender policing and thus impose a "male gaze" on each other in order to achieve a masculine status, to gain acceptance from other men (Flood 2008), and to avoid being stigmatised with a marginalised masculinity status (Connell 2005). However, the policing of other's behaviour found in our research was not intended to reinforce conformity to "masculine" behaviours but to study whether the "other's" behaviour was sexually correct. Therefore, the participants policed each other's behaviour not to reproduce hegemonic masculinity norms, but to challenge these norms and put forward a presentation of a respectable masculinity. Thus, men are challenging the heterosexual prowess element of hegemonic masculinity by self-policing their own behaviour or policing the behaviour of others.

On the other hand, some participants explain that their self-disciplining entails carving out spaces where they can act themselves. The labelling of safe and dangerous workplace colleagues operates as a "technology of self" (Foucault 1988). That is, these men operate within a set of pre-defined power relations (broad discourses of feminism) and find small spaces where they can continue presenting forms of masculinity that the \#MeToo movement aims to challenge. Instead of seeing this as potentially problematic, we agree with Foucault's (1977) conceptualisation of power as productive of social realities. We argue that instead of viewing such a source of power as one that "excludes ... represses ... censors" (Foucault 1977: 194), we can see such a power as one that liberates women from sexual harassment in the workplace.

\section{Conclusion}

Due to the importance of gender and power relations in contemporary society, research on masculinities, gender and workplace relations is crucial to developing knowledge in these fields. Despite the research limitations, this case study has provided a novel contribution of the impact of "\#MeToo" and sexual correctness in the workplace. The unique contribution of this research is that we found evidence of men in both mixed-sex and male-dominated occupations challenging the hegemonic construction of masculinity, particularly workplace performances of heterosexual prowess, as such behaviour is no longer perceived as "masculine" but more as "predatory". This is achieved by the policing of others' behaviour, whether to prevent transgressions or by embracing the contemporary attitude of sexual correctness in the workplace. However, we also found evidence of men exercising self-policing behaviours to circumvent scrutiny from the cultural power of contemporary feminism. 
Our research has limitations that make necessary further investigation in this area. The methodology was conducted in accordance with qualitative research, and thus the sample size was small. Therefore, the results cannot be generalised to the wider population. Additionally, the sample population consisted of mostly white, working- and middle-class men, employed in Glasgow. This is a limitation as the sample population was not diverse and thus the findings may be influenced by the demographics of the participants. It is also unclear if these findings are short-lived behavioural adaptations in the wake of \#MeToo or if they will remain a permanent feature of modern society, and thus further study to test this would be of benefit. Additional research on masculinities and gender relations within the workplace should be broadened to include a more diverse sample population, a larger sample size, including women and those of the LGBTQ + community, and to examine workplace regulations, instructions and disciplinaries relating to sexual harassment and misconduct as well as the impact upon the performance of masculinities in the wake of \#MeToo.

\section{Acknowledgements}

We would like to thank the participants in this research study who took the time to share their experiences with us. Additionally, we express our gratitude to the academic reviewers who helped shape this article.

\section{References}

Allan, Robert and Virginia Eatough. 2016. "The Use of Interpretative Phenomenological Analysis in Couple and Family Therapy Research." The Family Journal: Counselling and Therapy for Couples and Families 24(4): 406-414.

Back, Christina, Per A. Gustafsson, IngBeth Larsson, and Carina Berterö. 2011. "Managing the Legal Proceedings: An Interpretative Phenomenological Analysis of Sexually Abused Children's Experience with the Legal Process." Child Abuse and Neglect 35(1): 50-57.

Bagilhole, Barbara and Simon Cross. 2006. “'It Never Struck Me as Female': Investigating Men's Entry into Female-dominated Occupations.” Journal of Gender Studies 15(1): 35-48.

Bartky, Sandra L. 1998. "Foucault, Femininity, and the Modernisation of Patriarchal Power." Pp. 61-87 in Feminism and Foucault Reflections on Resistance, edited by I. Diamond and L. Quinby. New Jersey: Northeastern University Press.

Blair, Olivia. 2017. "Alicia Keys Expertly Shut down Adam Levine When He Questioned Her Nomakeup Stance." Independent. Retrieved December 3, 2018 (https://www.google.co.uk/amp/s/ www.independent.co.uk/life-style/alicia-keys-adam-levine-no-make-up-stance-shut-downresponse-questions-maroon-5-a7657541.html\%3famp).

Boyle, Karen. 2019. \#MeToo, Weinstein, and Feminism. London: Palgrave Pivot.

Boyle, Karen and Chamil Rathnayake. 2019. "\#HimToo and the Networking of Misogyny in the Age of \#MeToo." Feminist Media Studies 20(8): 25-50.

Bunsell, Tanya. 2013. Strong and Hard Women: An Ethnography of Female Bodybuilding. London: Routledge. 
Burke, Luise. 2018. "The \#MeToo Shockwave: How the Movement Has Reverberated around the World." The Telegraph. Retrieved March 10, 2018 (https://www.telegraph.co.uk/news/world/metooshockwave/).

Burnett, Zaron. 2018. "A Gentleman's Guide to the \#MeToo Era." Medium Equality. Retrieved August 14, 2019 (https://medium.com/s/man-interrupted/https-medium-com-zaron3-guide-tobeing-a-gentleman-in-the-metoo-era-f87ef12a9caa).

Buschmeyer, Anna and Diana Lengersdorf. 2016. "The Differentiation of Masculinity as a Challenge for the Concept of Hegemonic Masculinity.” International Journal for Masculinity Studies 11(3): 190207.

Campbell, Elaine. 2003. "Interviewing Men in Uniform: A Feminist Approach?” International Journal of Social Research Methodology 6(4): 285-304.

Civitello, A. 2017. "\#MeToo Confronting Sexual Harassment in the Public Library." Best Practices 56(5): 9-10.

Connell, Robert W. and James W. Messerschmidt. 2005. "Hegemonic Masculinity: Rethinking the Concept." Gender and Society 19(6): 829-259.

Collins, Erika. 2020. "The Global Impact of \#MeToo Movement." The Law Reviews. The Employment and Law Review (11): 1-25.

Connell, Robert W. 1992. "A Very Straight Gay: Masculinity, Homosexual Experience, and the Dynamics of Gender.” American Sociological Review 57(6): 735-751.

Connell, Robert. 2005. Masculinities. 2nd Edition. Cambridge: Polity Press.

Cross, Simon and Barbara Bagilhole. 2002. “'Girls'Jobs for the Boys? Men, Masculinity and Nontraditional Occupations." Gender, Work and Organisation 9(2): 1-25.

England, Kim. 1994. "Getting Personal: Reflexivity, Positionality, and Feminist Research." The Professional Geographer 46(1): 80-89.

Evans, Lorraine and Kimberly Davies. 2000. "No Sissy Boys Here:AContent Analysis of the Representation of Masculinity in Elementary School Reading Textbooks." Sex Roles 42(3): 255-270.

Fernández-Morales, Marta and María Isabel Menéndez-Menéndez. 2016. "“When in Rome, Use What've Got': A Discussion of Female Agency through Orange is the New Black." Television and New Media 17(6): 534-536.

Flick, Uwe. 2014. The Sage Handbook of Qualitative Data Analysis. London: Sage Publications Ltd.

Flood, Michael. 2008. "Men, Sex and Homosociality, How Bonds Between Men Shape Their Sexual Relations with Women." Men and Masculinities 10(3): 339-359.

Foucault, Michel. 1977. Discipline and Punish: The Birth of the Prison. London: Penguin.

Foucault, Michel. 1979. The History of Sexuality Volume 1: An Introduction. London: Penguin Books Ltd.

Foucault, Michel. 1980. "The Eye of Power." Pp. 146-165 in Michel Foucault Power/Knowledge: Selected Interviews and Other Writings 1972-1977, edited by C. Gordon. Suffolk: The Harvester Press Limited.

Foucault, Michel. 1988. Technologies of the Self: A Seminar with Michel Foucault. Edited by L. H. Martin, H. Gutman, and P. H. Hutton. Amherst: University of Massachusetts Press.

Furedi, Frank. 1997. The Culture of Fear Revisited. London: Cromwell Press Ltd.

Gailey, Jeannine A. and Ariane Prohaska. 2011. "Power and Gender Negotiations during Interviews with Men about Sex and Sexually Degrading Practices." Qualitative Research 11(4): 365-380.

Giaccardi, Soraya, L. Monique Ward, Rita C. Seabrook, Adriana Manago, and Julia Lippman. 2016. "Media and Modern Manhood: Testing Associations Between Media Consumption and young Men's Acceptance of Traditional Gender Ideologies.” Sex Roles 75(3): 151-163.

Gramsci, Antonio. 1971. Selections from the Prison Notebooks. New York: International Publishers. 
Grazian, David. 2007. "The Girl Hunt: Urban Nightlife and the Performance of Masculinity as Collective Activity." Symbolic Interaction 30(2): 221-243.

Grbich, Carol. 2013. Qualitative Data Analysis: An Introduction. 2nd Edition. London: Sage Publications Ltd.

Griffin, Christine. 2000. "Discourses of Crisis and Loss: Analysing the 'Boys Underachievement' Debate." Journal of Youth Studies 3(2): 167-188.

Hess, Aaron, Lisa Menegatos, and Matthew W. Savage. 2015. "Shaming Jane: A Feminist Foucauldian Analysis of How College Students Employ the Sexual Double Standard in Peer Interventions." Women's Studies in Communications 38(4): 462-485.

Hooks, Bell. 2000. Feminism is for Everybody: Passionate Politics. London: Pluto Press.

Hopkins, Peter E. 2009. "Responding to the 'Crisis of Masculinity': The Perspectives of Young Muslim Men from Glasgow and Edinburgh, Scotland." Gender, Place and Culture 16(3): 299-312.

Johnston, Cathal and Todd G. Morrison. 2007. "The Presentation of Masculinity in Everyday Life: Contextual Variations in the Masculine Behaviour of Young Irish Men." Sex Roles 57(9): 661-674.

Jones, Colin and Roy Porter, eds. 1994. Reassessing Foucault Power, Medicine and the Body. London: Routledge.

Jordan, Ana. 2014. “"Every Father is a Superhero to His Children': The Gendered Politics of the (Real) Fathers 4 Justice Campaign." Political Studies 62(1): 83-98.

Jordan, Ana and Amy Chandler. 2018. "Crisis, What Crisis? A Feminist Analysis of Discourse on Masculinities and Suicide." The Journal of Gender Studies 10: 1-14.

Kim, Janna L., C. Lynn Sorsoli, Katherine Collins, Bonnie A. Zylbergold, Deborah Schooler, and Deborah L. Tolman. 2007. "From Sex to Sexuality: Exposing the Heterosexual Script on Primetime Network Television." Journal of Sex Research 44(2): 145-157.

Knight, Matthew T. D., Til Wykes, and Peter Hayward. 2003. "People Don't Understand': An Investigation of Stigma in Schizophrenia using Interpretative Phenomenological Analysis (IPA)." Journal of Mental Health 12(3): 209-222.

Lincoln, Yvonna S. and Egon G. Guba. 1985. Naturalistic Inquiry. Newbury Park, CA: Sage.

Lupton, B., 2000. "Maintaining Masculinity: Men who do Women's Work". British Journal of Management 11(Special Issue): 33-48.

Lupton, Deborah. 2015. Digital Sociology. Oxon: Routledge.

McCarthy, Lauren. 2017. "Empowering Women through Corporate Social Responsibility: A Feminist Foucauldian Critique.” Business Ethics Quarterly 27(4): 603-631.

McDowell, Joanne. 2015. "Masculinity and non-Traditional Occupations: Men's Talk and Women's Work." Gender, Work and Organisation 22(3): 273-291.

McDowell, Linda. 2000. "The Trouble with Men? Young People, Gender Transformations and the Crisis of Masculinity." International Journal of Urban and Regional Research 24(1): 201-209.

McDowell, Linda. 2000. "Learning to Serve? Employment Aspirations and Attitudes of Young WorkingClass Men in an Era of Labour Market Restructuring." Gender, Place and Culture: A Journal of Feminist Geography 7(4): 389-416.

McElroy, Wendy. 1996. Sexual Correctness: The Gender Feminist Attack on Women. North Carolina: McFarland \& Company Inc.

McMillan, Lesley. 2013. "Sexual Victimisation: Disclosure, Responses and Impact." Pp. 71-86 in Violence Against Women: Current Theory and Practice in Domestic Abuse, Sexual Violence and Exploitation, edited by A. Gill et al. London: Jessica Kingsley.

McNay, Lois. 1992. Foucault and Feminism: Power, Gender and the Self. Cambridge: Polity Press.

Murnen, Sarah K. 2015. "A Social Constructivist Approach to Understanding the Relationship Between Masculinity and Sexual Aggression.” American Psychological Association 16(4): 370-373. 
Nguyen,Athena. 2008. "Patriarchy, Power, andFemale Masculinity.” Journal of Homosexuality 55(4): 665683.

Parker, N. 2017. "Who is Tarana Burke? Meet the Women who Started the MeToo Movement a Decade Ago." The Atlanta Journal-Constitution. Retrieved October 10, 2018 (https://www.ajc.com/ news/world/who-tarana-burke-meet-the-woman-who-started-the-too-movement-decade-ago/ i8NEiuFHKaIvBh9ucukidK/).

Pascoe, Cheri Jo. 2005. "'Dude, You're a Fag': Adolescent Masculinity and the Fag Discourse." Sexualities 8(3): 329-346.

Phillips, Debby. 2007. "Punking and Bullying Strategies in Middle School, High School, and Beyond." Journal of Interpersonal Violence 22(2): 158-178.

Pini, Barbara. 2005. "Interviewing Men: Gender and the Collection and Interpretation of Qualitative Data." Journal of Sociology 4(2): 201-216.

Quinn, Beth. 2002. "Sexual Harassment and Masculinity: The Power and Meaning of 'Girl Watching,." Gender \& Society 16(3): 386-402.

Roberts, Steven. 2012. "Boys Will Be Boys ... Won't They? Change and Continuities in Contemporary Young Working-class Masculinities.” Sociology and Social Research 47(4): 671-686.

Singleton, Andrew. 2008. "Boys in Crisis? Australian Adolescent Males Beyond the Rhetoric.” Journal of Men's Studies 15(3): 361-373.

Suarez, Eliana and Tahany M. Gadalla. 2010. "Stop Blaming the Victim: A Meta-Analysis on Rape Myths.” Journal of Interpersonal Violence 25(11): 2010-2035.

Tretheway, Angela. 1999. "Disciplined Bodies: Women's Embodied Identities at Work." Social Science Collections 20(3): 423-450.

Walby, Sylvia. 2003. Gender Transformations. London: Routledge.

Ward, L. Monique. 1995. "Talking about Sex: Common Themes about Sexuality in the Prime-Time Television Programs Children and Adolescents View Most." Journal of Youth and Adolescence 24(5): 595-615.

West, Candace and Don H. Zimmerman. 1987. "Doing Gender." Gender and Society 1(2): 125-151.

Williams, Joanna. 2017. “The \#Metoo Movement Reveals Feminism's Obsession with Victimhood.” The Spectator. Retrieved August 14, 2019 (https://blogs.spectator.co.uk/2017/10/the-metoo-movementreveals-feminisms-obsession-with-victimhood/).

Winlow, Simon. 2001. Badfellas: Crime, Tradition and New Masculinities. Oxford: Berg Publishers.

Verhoeven, Deb, Bronwyn Coate, and Vejune Zemaityte. 2019. "Re-Distributing Gender in the Global Film Industry: Beyond \#Metoo and \#Methree." Media Industries Journal 6(1): 135-155.

Young, Iris Marion. 1980. "Throwing Like a Girl: A Phenomenology of Feminine Bodily Comportment Motility and Spatiality." Human Studies 3(1): 137-156.

Zacchia, Giulia, Marcella Corsi, and Fabrizio Botti. 2019. "The Complexity of \#MeToo: The Evolution of a Twitter Campaign in Europe.” Pp. 12-37 in The \#MeToo Social Media Effect and its Potentials for Social Change in Europe, edited by Marcella Corsi, Laeticia Thissen, and Giulia Zacchia. Brussels: FEPS - Foundation for European Progressive Studie, Rome: Fondazione Socialismo.

\section{Authors}

Nicole Graham graduated from Glasgow Caledonian University in 2019 and is now an independent researcher whilst employed by the City of Glasgow College. Her research interests include the sociologies of gender and crime, gender-based violence, victimology, and Foucauldian theory.

Contact: nicolegraham2610@outlook.com 
James Bowness is an independent researcher with an interest in the sociologies of sport, physical activity, and education. He is a former lecturer in sociology and social policy and completed his PhD in 2017.

Contact: jamesbo800@yahoo.co.uk 